\title{
False killer whale and short-finned pilot whale acoustic identification
}

\author{
Simone Baumann-Pickering ${ }^{1, *}$, Anne E. Simonis ${ }^{1}$, Erin M. Oleson ${ }^{2}$, Robin W. Baird ${ }^{3}$, \\ Marie A. Roch ${ }^{1,4}$, Sean M. Wiggins ${ }^{1}$ \\ ${ }^{1}$ Scripps Institution of Oceanography, University of California, San Diego, 9500 Gilman Drive, La Jolla, California 92093-0205, USA
${ }^{2}$ Pacific Islands Fisheries Science Center, NOAA, 2570 Dole Street, Honolulu, Hawai'i 96822, USA
${ }^{3}$ Cascadia Research Collective, 218 1/2 W 4th Ave, Olympia, WA 98501, USA
${ }^{4}$ Department of Computer Science, San Diego State University, 5500 Campanile Drive, San Diego, California 92182-7720, USA
}

ABSTRACT: False killer whales Pseudorca crassidens and short-finned pilot whales Globicephala macrorhynchus are known to interact with long-line fishing gear in Hawaiian waters, causing economic loss and leading to whale injuries and deaths. The main Hawaiian Islands' insular population of false killer whales is listed as endangered and the offshore population is considered 'strategic' under the Marine Mammal Protection Act due to relatively high bycatch levels. Discriminating between these species acoustically is problematic due to similarity in the spectral content of their echolocation clicks. We used passive acoustic monitoring along with data from satellite tags to distinguish signals from these 2 species. Acoustic encounters recorded with autonomous instruments offshore of the islands of Hawai'i and Kaua'i were matched with concurrent and nearby location information obtained from satellite tagged individuals. Two patterns of echolocation clicks were established for the 2 species. The overall spectral click parameters were highly similar $(22 \mathrm{kHz}$ peak and $25 \mathrm{kHz}$ center frequency), but false killer whales had shorter duration and broader bandwidth clicks than short-finned pilot whales $(225 \mu \mathrm{s}, 8 \mathrm{kHz}$ [ $-3 \mathrm{~dB}$ bandwidth] and $545 \mu \mathrm{s}$, $4 \mathrm{kHz}$, respectively). Also, short-finned pilot whale clicks showed distinct spectral peaks at 12 and $18 \mathrm{kHz}$. Automated classification techniques using Gaussian mixture models had a $6.5 \%$ median error rate. Based on these findings for echolocation clicks and prior published work on whistle classification, acoustic encounters of false killer whales and short-finned pilot whales on autonomous instruments should be identifiable to species level, leading to better long-term monitoring with the goal of mitigating bycatch.

KEY WORDS: Echolocation - Classification - False killer whale - Passive acoustic monitoring • Satellite tagging

\section{INTRODUCTION}

False killer whales Pseudorca crassidens and shortfinned pilot whales Globicephala macrorhynchus are known to interact with pelagic long-line fisheries in Hawaiian waters, causing economic loss to the fishing industry and at least occasionally resulting in injury or death to the animals (Forney et al. 2011). Since both of these species are known to echolocate, passive acoustic monitoring techniques are being

\footnotetext{
*Corresponding author: sbaumann@ucsd.edu
}

evaluated to assess the suitability of this method for distinguishing species, and potentially for bycatch mitigation.

Both species occur in largely overlapping distributions in tropical to warm temperate waters of all oceans, generally in more offshore and deep waters (Jefferson et al. 2008), where long-line fishing is conducted. The behavior, ecology, and social structure of these species have been studied most extensively around the Hawaiian archipelago (Baird 2009, Baird

() The authors 2015. Open Access under Creative Commons by Attribution Licence. Use, distribution and reproduction are unrestricted. Authors and original publication must be credited. Publisher: Inter-Research · www.int-res.com 
et al. 2010, 2012, 2013a,b, Bradford et al. 2014, Mahaffy et al. 2015). Behavioral and genetic evidence indicates 3 distinct populations of false killer whales in Hawaiian waters, with an insular main Hawaiian Islands stock, a pelagic, offshore stock, and a Northwestern Hawaiian Islands stock (Chivers et al. 2010, Baird et al. 2012, 2013a, Bradford et al. 2014, Martien et al. 2014). Fishery interactions and other threats have led to the listing of the main Hawaiian Island population of false killer whales as 'endangered' (November 2012 77FR 70915) under the US Endangered Species Act (ESA), and the pelagic stock as 'strategic' under the US Marine Mammal Protection Act (Bradford et al. 2014, Carretta et al. 2014).

A take reduction team was formed by the US National Marine Fisheries Service in 2010. One of its primary research goals is distinguishing false killer whale acoustic signals from those of other toothed whales (November 201277 FR 71259). Delphinids produce 2 general types of signals: (1) tonal frequency-modulated signals (whistles), and (2) broadband pulsed signals (clicks) (Herman \& Tavolga 1980). Whistles are primarily used for communication, whereas echolocation clicks are used for detection, localization, and target classification in spatial orientation and foraging (e.g. Herman \& Tavolga 1980, Au 1993). Field recordings of false killer whale and short-finned pilot whale whistles have been successfully discriminated, and automated classification routines were developed (Rendell et al. 1999, Oswald et al. 2003, 2007). However, misclassification most often occurred with whistles originating from shortfinned pilot whales. The characteristics of false killer whale echolocation clicks have been described (e.g. $\mathrm{Au}$ et al. 1995, Madsen et al. 2004, Ibsen et al. 2011) and false killer whale echolocation capabilities have mainly been studied with captive animals (e.g. Thomas \& Turl 1990, Brill et al. 1992, Yuen et al. 2005, Kloepper et al. 2012, Madsen et al. 2013). The overall spectral content of their clicks seems to be generally lower than what is known for most other echolocating delphinids, having considerable energy below $20 \mathrm{kHz}$. While the echolocation strategy of short-finned pilot whales during deep dives is known to consist of foraging sprints accompanied by clicking, buzzing, and communication signals (Aguilar Soto et al. 2008, Jensen et al. 2011), no spectral or temporal information on short-finned pilot whale echolocation clicks is available. Assuming a similar spectral content of echolocation clicks from short-finned pilot whales as described for long-finned pilot whales Globicephala melas (Eskesen et al. 2011), discrimination of shortfinned pilot whale clicks from false killer whale clicks may be problematic based on spectral content. However, the capability to determine species identity from echolocation clicks can enhance passive acoustic monitoring and real-time alert systems. This is particularly true during periods when animals are echolocating without whistling and when combining both vocal production types in the classification decision.

The goal of this study was to describe the differences in echolocation click characteristics between false killer whales and short-finned pilot whales and demonstrate reliable classification results for clicks of these 2 species. This was accomplished by reviewing long-term acoustic recordings taken offshore of the main Hawaiian Islands and comparing these to concurrent and nearby satellite tracking tagged false killer whales and short-finned pilot whales for specieslevel echolocation click identification. These clicks were then used to build classification models which can be applied to acoustic recordings without the necessity of ground-truthing tagged animals.

\section{MATERIALS AND METHODS}

\section{Acoustic recordings}

Autonomous high-frequency acoustic recording packages (HARPs) were bottom-moored at 2 locations in the main Hawaiian Islands at water depths of 600 to $700 \mathrm{~m}$, with the hydrophone positioned about $30 \mathrm{~m}$ above the seafloor. One recorder location was offshore of the west coast of the island of Hawai'i (19 ${ }^{\circ}$ $34.9^{\prime} \mathrm{N}, 156^{\circ} 00.9^{\prime} \mathrm{W}$ ) and the other was between the

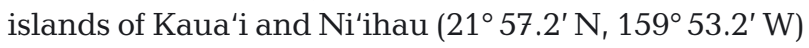
(Fig. 1). There were a number of deployments from August 2007 to May 2010 with varying recording schedules (Table 1). The instruments were part of a larger study to monitor cetacean and anthropogenic sounds over long periods near the Hawaiian Islands.

HARPs were set to a sampling frequency of $200 \mathrm{kHz}$ with 16-bit quantization. The recorders were equipped with an omni-directional sensor (ITC-1042, International Transducer Corporation), which had an approximately flat $( \pm 2 \mathrm{~dB})$ hydrophone sensitivity from $10 \mathrm{~Hz}$ to $100 \mathrm{kHz}$ of $-200 \mathrm{~dB}$ re $\mathrm{V} / \mu \mathrm{Pa}$. The sensor was connected to a custom-built preamplifier board and bandpass filter. The preamplifiers were designed to flatten the frequency response of the ambient ocean noise, which provided greater gain at higher frequencies where ambient noise levels are lower and sound attenuation is higher (Wiggins \& Hildebrand 2007). The calibrated system response was accounted for during analysis. 


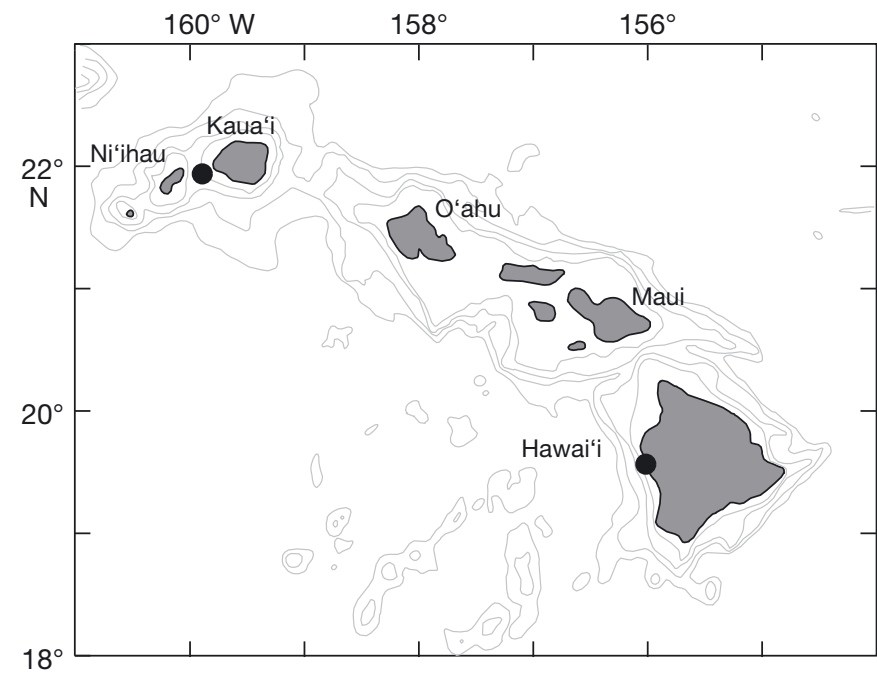

Fig. 1. Main Hawaiian Islands with high-frequency acoustic recording package (HARP) locations (black dots). Grey bathymetry lines: $1000 \mathrm{~m}$

\section{Satellite tagging and location analysis}

Details of the satellite tags and tagging methods have been previously published (Baird et al. 2010, 2012), so they are only briefly reviewed here. Satellite tags containing an ARGOS-linked, Wildlife Computers (Redmond) location-only SPOT-5 transmitter were remotely deployed on both species using a pneumatic projector. Tags were attached with two $6.5 \mathrm{~cm}$ titanium attachment darts. Location data obtained from Argos were assessed for plausibility with the Douglas Argos-Filter v.7.06 using established parameters (Baird et al. 2010, 2012). Straight-line distances between filtered whale locations and the HARP locations were determined for periods when HARP acoustic and whale location data overlapped, using the Posdist macro in Microsoft Excel (www. afsc.noaa.gov/nmml/software/excelgeo.php). Consecutive tagged whale locations that spanned the

Table 1. Deployment periods of high-frequency acoustic recording packages (HARPs) at sites offshore of Hawai'i $\left(19^{\circ} 34.9^{\prime} \mathrm{N}, 156^{\circ} 00.9^{\prime} \mathrm{W}\right)$ and Kaua'i $\left(21^{\circ} 57.2^{\prime} \mathrm{N}, 159^{\circ} 53.2^{\prime} \mathrm{W}\right)$ with overlapping periods of satellite tag recording. Recording start and end dates and times given as mm/dd/yy, GMT

\begin{tabular}{|llcccc|}
\hline Index & Site & $\begin{array}{c}\text { Depth } \\
(\mathrm{m})\end{array}$ & $\begin{array}{c}\text { Duty cycle } \\
\text { (on/period) (min) }\end{array}$ & Recording start & Recording end \\
\hline 1 & Hawai'i & 630 & Continuous & 08/11/07, 00:00 & $10 / 04 / 07,06: 17$ \\
2 & Hawai'i & 650 & $5 / 15$ & $07 / 08 / 08,00: 00$ & $10 / 15 / 08,20: 48$ \\
3 & Hawai'i & 620 & $5 / 15$ & $04 / 23 / 09,10: 00$ & $08 / 18 / 09,17: 48$ \\
4 & Hawai'i & 620 & Continuous & $10 / 25 / 09,00: 00$ & $12 / 15 / 09,22: 16$ \\
5 & Hawai'i & 620 & $5 / 12$ & $12 / 20 / 09,00: 00$ & $03 / 05 / 10,16: 03$ \\
6 & Kaua'i & 700 & $5 / 20$ & $10 / 08 / 09,00: 00$ & $05 / 13 / 10,01: 00$ \\
\hline
\end{tabular}

HARP location (e.g. north and south of the HARP) were used to assess periods when whale movements past the HARP may have occurred and resulted in acoustic recordings of that whale or individuals of its group. While we cannot be certain how many animals were within the detection range of our recorder, the number of individuals recorded during each acoustic encounter is expected to be more than just the single tagged animal. Group sizes of false killer whale and short-finned pilot whales around the main Hawaiian Islands average $15.6 \pm 8.8$ and $20.0 \pm 15.6$ individuals, respectively (Baird et al. 2013b).

\section{Acoustic data analysis and satellite tag location match}

Signal processing was performed using the MATLAB (Mathworks) based custom software program Triton (Wiggins \& Hildebrand 2007) and other MATLAB custom routines. Long-term spectral averages (LTSAs) were calculated for visual analysis of the long-term recordings. LTSAs are long-term spectrograms with each time segment consisting of an average of 500 spectra, which were created using the Welch algorithm (Welch 1967). The averages were formed from the power spectral densities of nonoverlapped $10 \mathrm{~ms}$ Hann-windowed frames. The resulting long-term spectrograms have a resolution of $100 \mathrm{~Hz}$ in frequency and $5 \mathrm{~s}$ in time. This averaging technique provides visual detectability of echolocation activity in a $5 \mathrm{~s}$ bin containing as few as 1 or 2 clicks. Trained analysts (A.E.S., S.B.P.) manually screened $1 \mathrm{~h}$ windows of LTSAs and identified echolocation acoustic encounters in the HARP data when echolocation click energy fell below $20 \mathrm{kHz}$. This criterion was chosen based on towed hydrophone recordings in the presence of short-finned pilot whales in which echolocation click energy was below $20 \mathrm{kHz}$ (authors' unpubl. data). Images of these LTSAs were saved, and start and end times of acoustic encounters were noted.

For each acoustic encounter, it was noted if satellite tag locations were reported within 5 nautical miles and $3 \mathrm{~h}$ prior or subsequent to the encounter. Based on the time difference between the tag location and the start or end of the acoustic recording, these encounters were labeled as potential encounters of the tagged species with low (1 to $3 \mathrm{~h}$ ) or high (0 to $1 \mathrm{~h}$ ) confidence (and will be shown to be similar 
to one another via classification experiment). Only echolocation clicks from high confidence acoustic encounters were used to compute echolocation click parameters.

Individual echolocation signals within these selected encounters were automatically detected using a 2 step approach computer algorithm (Soldevilla et al. 2008, Roch et al. 2011). The individual click detections were digitally filtered with a 10 pole Butterworth band-pass filter with a pass-band between 5 and $95 \mathrm{kHz}$. Filtering was done on 800 sample points centered on the echolocation signal. Spectra of each detected signal were calculated using $2.56 \mathrm{~ms}$ (512 samples) of Hann-windowed data centered on the signal. The frequency-related signal parameters peak frequency, center frequency, and bandwidth $(-3$ and $-10 \mathrm{~dB})$ were processed using methods from $\mathrm{Au}$ (1993). Click duration was derived from the detector output. All detected echolocation signals, independent of distance and orientation of the recorded animal with respect to the recorder, were included in the analysis. Mean spectra were computed for all clicks across all acoustic encounters for each species. Mean noise spectra were also estimated from $2.56 \mathrm{~ms}$ of the 5 to $95 \mathrm{kHz}$ bandpass-filtered acoustic signal (512 samples) ending $1.3 \mathrm{~ms}$ before the signal, similar to the echolocation click.

\section{Classification}

The classification methodology, which uses Gaussian mixture models (GMMs), is similar to that reported in Roch et al. (2011), but was modified to increase the variability of training data to better measure the susceptibility of the classifier to overtraining. Features consisted of duration and 14 cepstral coefficients that provide a compact representation of the spectra (Roch et al. 2011) extracted from the spectra of each echolocation click between 10 and $92 \mathrm{kHz}$.

Subsets of data from the high confidence acoustic encounters were used to train 16 mixture GMMs. For each species, the acoustic encounters were randomly permuted and distributed as evenly as possible into 3 groups for a 3 -fold cross-validation experiment. For each of the 3 trials, the 2 folds used for training were further reduced by a random draw with replacement (a click could be selected more than once) of $85 \%$ of the echolocation clicks. The encounters from the remaining fold were then classified using the shortfinned pilot and false killer whale models. For each encounter in the test fold, joint probabilities were computed for each of the 2 models for groups of 100 echolocation clicks, making the simplifying assumption that echolocation clicks are independent. Click groups were assigned to species based on the Bayes decision rule (the model that produced the maximum probability). This process was repeated 100 times, resulting in 300 individual experiments. The low confidence acoustic encounters were classified using the 300 models trained from subsets of the high confidence models.

\section{RESULTS}

Satellite-tagged false killer whales and shortfinned pilot whales utilized the areas within the vicinity of the HARPs on a number of occasions and were matched with acoustic encounters containing click energy below $20 \mathrm{kHz}$ (Tables 2 \& 3, Figs. 2 \& 3). Satellite-derived positions from 10 individual false killer whales and 15 individual short-finned pilot whales were matched with acoustic encounters. High and low confidence matches were achieved for 7 and 6 acoustic encounters with false killer whale locations (Table 2) and 15 and 3 acoustic encounters with short-finned pilot whale locations (Table 3), respectively.

The spectral echolocation click parameters peak and center frequency were highly similar when comparing clicks extracted from all high confidence acoustic encounters of both species (Table 4). False killer whale echolocation clicks had a much broader bandwidth but shorter duration clicks, resulting in a similar time-bandwidth product (a metric of signal processing gain). The LTSAs and mean spectra of acoustic encounters that were matched with shortfinned pilot whale showed spectral banding with peaks at 12 and $18 \mathrm{kHz}$ (Fig. 4A,B). These spectral peaks were absent in encounters matched with false killer whales. When examining individual echolocation clicks of both species, presumable off-axis echolocation clicks of short-finned pilot whales appeared with more cycles in the waveform and with a slight frequency modulation (Fig. 4D).

GMM classification of echolocation clicks from high confidence acoustic encounters resulted in a $6.5 \%$ median (mean $7.9 \pm 8.0 \%$ ) error rate across the 300 randomized trials. Performance on individual species in an accept/reject task had a median classification error of $2.8 \%$ (mean $7.5 \pm 14.7 \%$ ) for false killer whales, which was slightly lower than the error for short-finned pilot whales (median $3.9 \%$, mean $7.6 \pm$ $10.2 \%$ ) (Fig. 5A). Classification of low confidence acoustic encounters using the models trained on high 


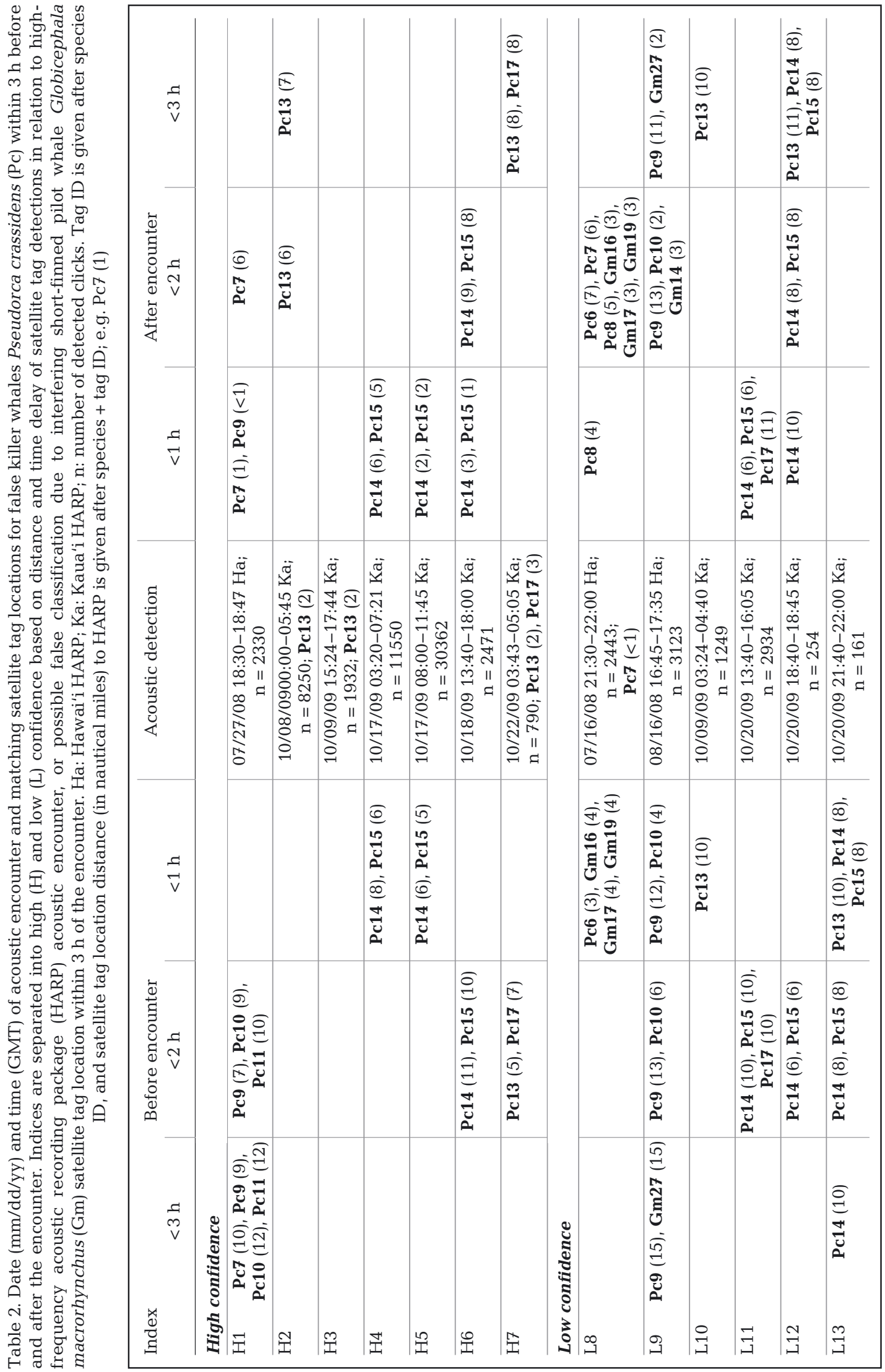




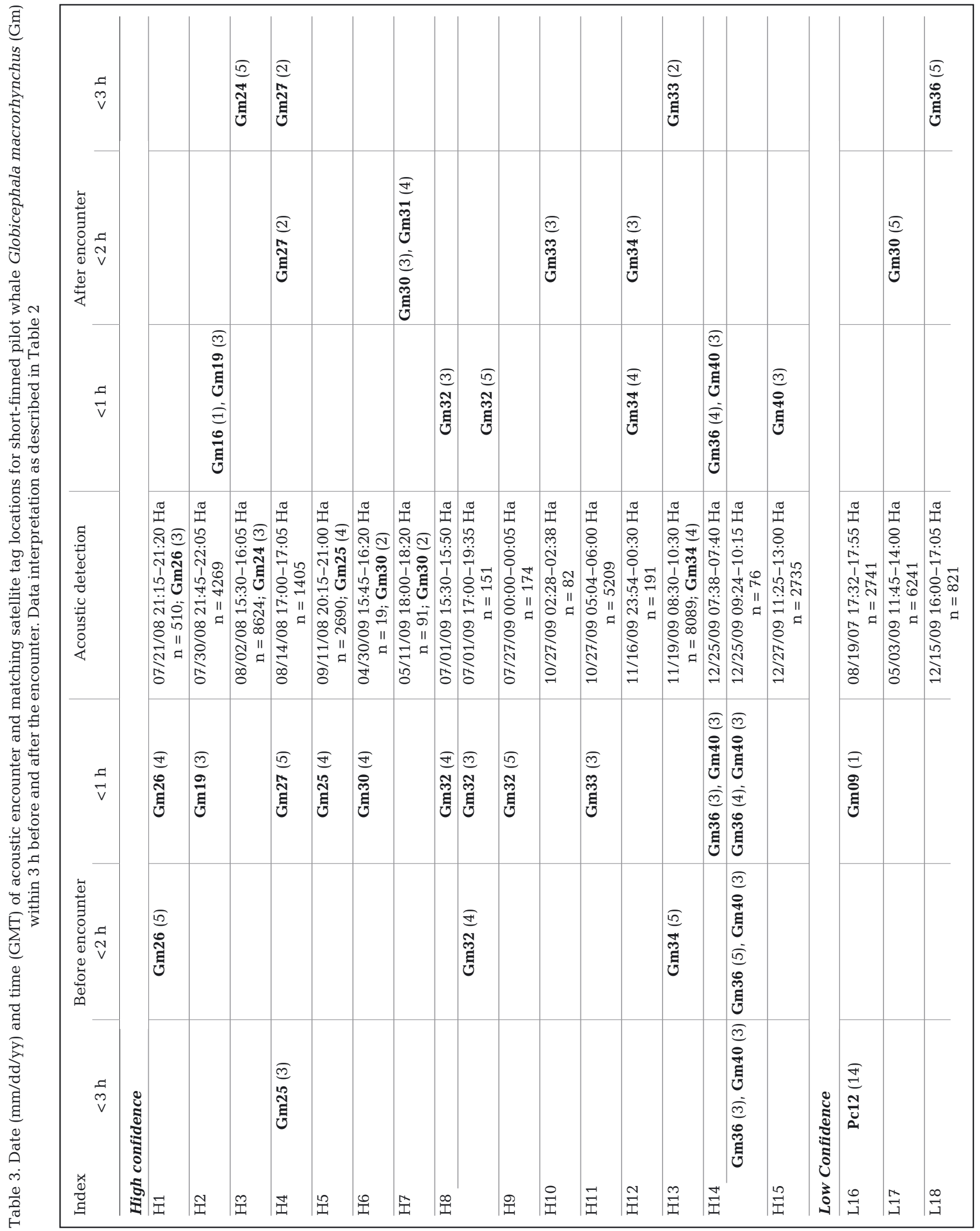



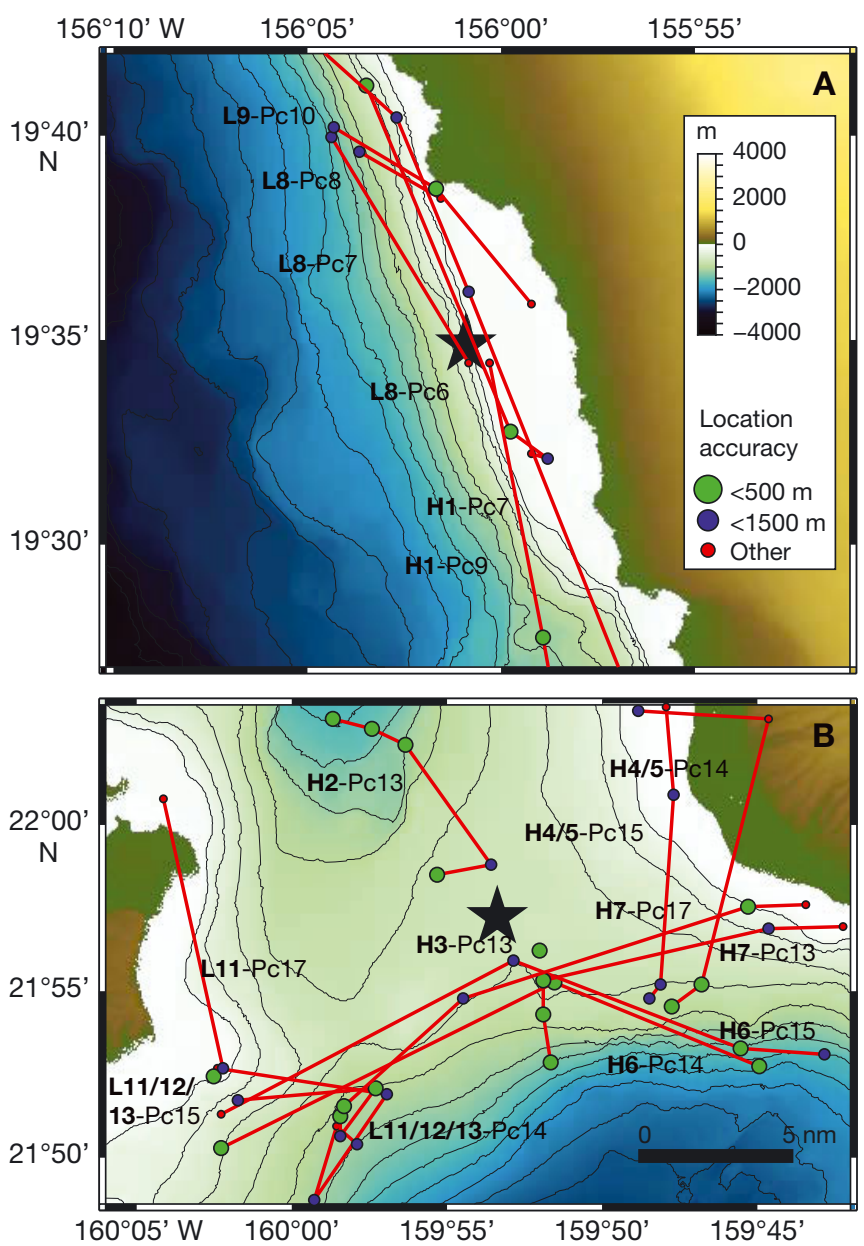

Fig. 2. Satellite tag locations and paths of false killer whales Pseudorca crassidens ( $\mathrm{Pc}$ ) with tag ID (e.g. Pc10) and associated acoustic encounter on high-frequency acoustic recording package (HARP) locations (star) (e.g. L9, see Table 2). Animal location accuracy is indicated by the size and color of filled circles. Bathymetry lines: $200 \mathrm{~m}$

confidence encounters resulted in better classification performance with the median error reduced to $2.6 \%$ (mean $3.9 \pm 7.0 \%$; false killer whale: median $0.0 \%$, mean $3.2 \pm 1.4 \%$; short-finned pilot whale: median $4.1 \%$, mean $4.7 \pm 3.6 \%$ ) (Fig. 5B).

Table 4. Echolocation click parameter median and $10^{\text {th }}$ to $90^{\text {th }}$ percentile values for false killer whales Pseudorca crassidens and short-finned pilot whales Globicephala macrorhynchus

\begin{tabular}{|lccc|}
\hline & Unit & $\begin{array}{c}\text { False killer } \\
\text { whale }\end{array}$ & $\begin{array}{c}\text { Short-finned } \\
\text { pilot whale }\end{array}$ \\
\hline Peak frequency & $\mathrm{kHz}$ & $21.5(7.8-33.6)$ & $21.9(7.8-39.1)$ \\
Center frequency & $\mathrm{kHz}$ & $24.9(17.6-33.7)$ & $25.2(19.2-35.5)$ \\
-3dB bandwidth & $\mathrm{kHz}$ & $7.8(3.5-17.2)$ & $4.3(2.3-9.4)$ \\
-10dB bandwidth & $\mathrm{kHz}$ & $21.1(6.6-39.5)$ & $9.8(3.9-24.2)$ \\
Duration & $\mu \mathrm{s}$ & $225(125-530)$ & $545(160-1225)$ \\
\hline
\end{tabular}
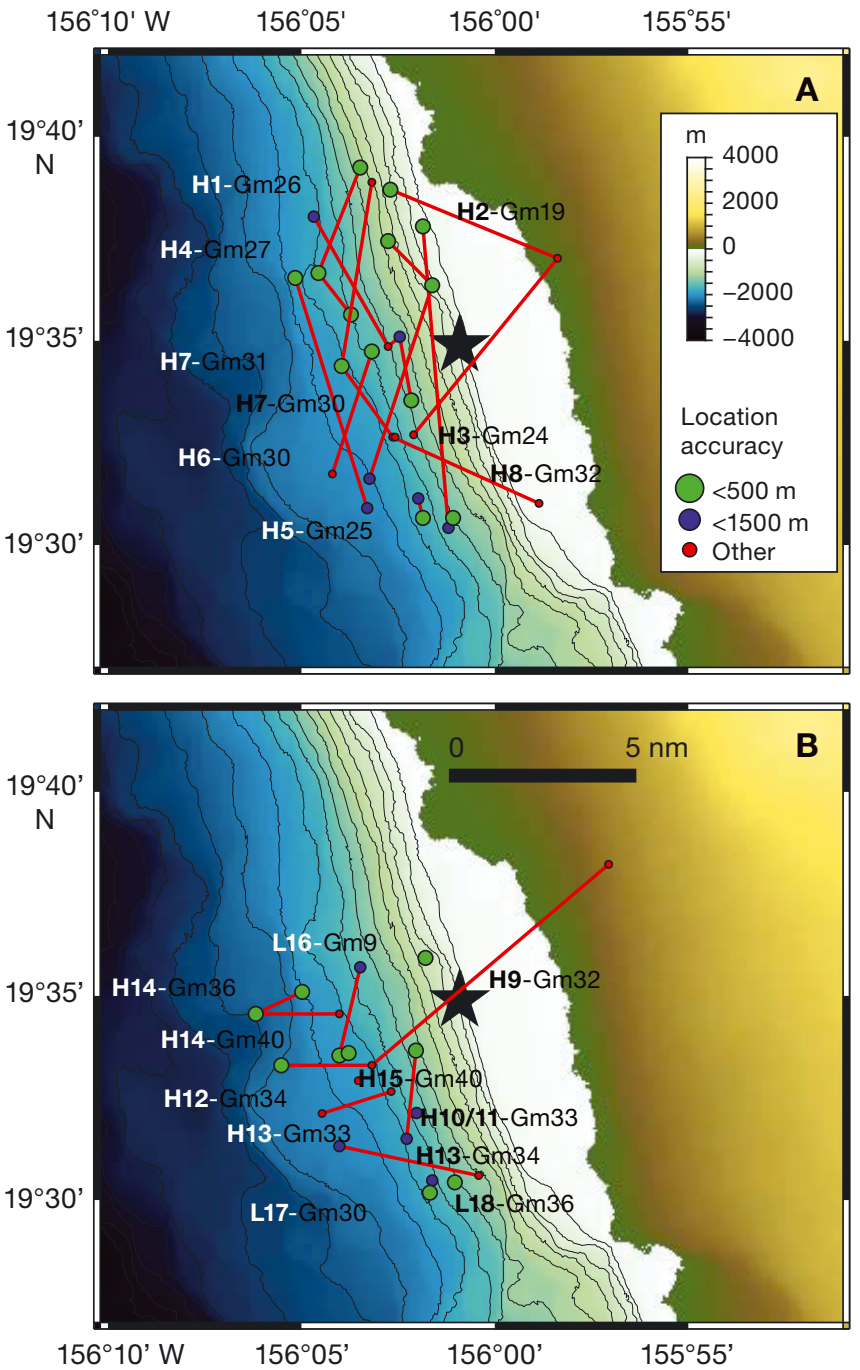

Fig. 3. Satellite tag locations and resulting paths of shortfinned pilot whales Globicephala macrorhynchus (Gm) with tag ID (e.g. GM26) and associated acoustic encounter on high-frequency acoustic recording package (HARP) locations (star) (e.g. H1, see Table 3). Animal location accuracy is indicated by the size and color of filled circles. Bathymetry lines: $200 \mathrm{~m}$

\section{DISCUSSION}

Acoustic recordings from bottom-moored autonomous instruments in combination with locations of satellite tagged individuals from 2 odontocete species in the vicinity of the recorder have proven to be a useful method for gathering species-specific recordings for descriptions of their acoustic signals. Uncertainty remains, however, whether the recorded signals truly belong to the tagged individual(s) and their conspecifics or rather to other species concurrently in the detection range of the recorder. The 2 species rarely associate in Hawaiian waters; in 50 
False killer whale

A

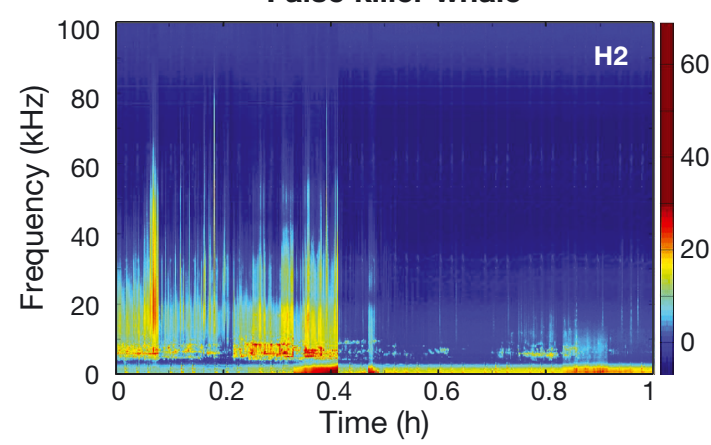

B
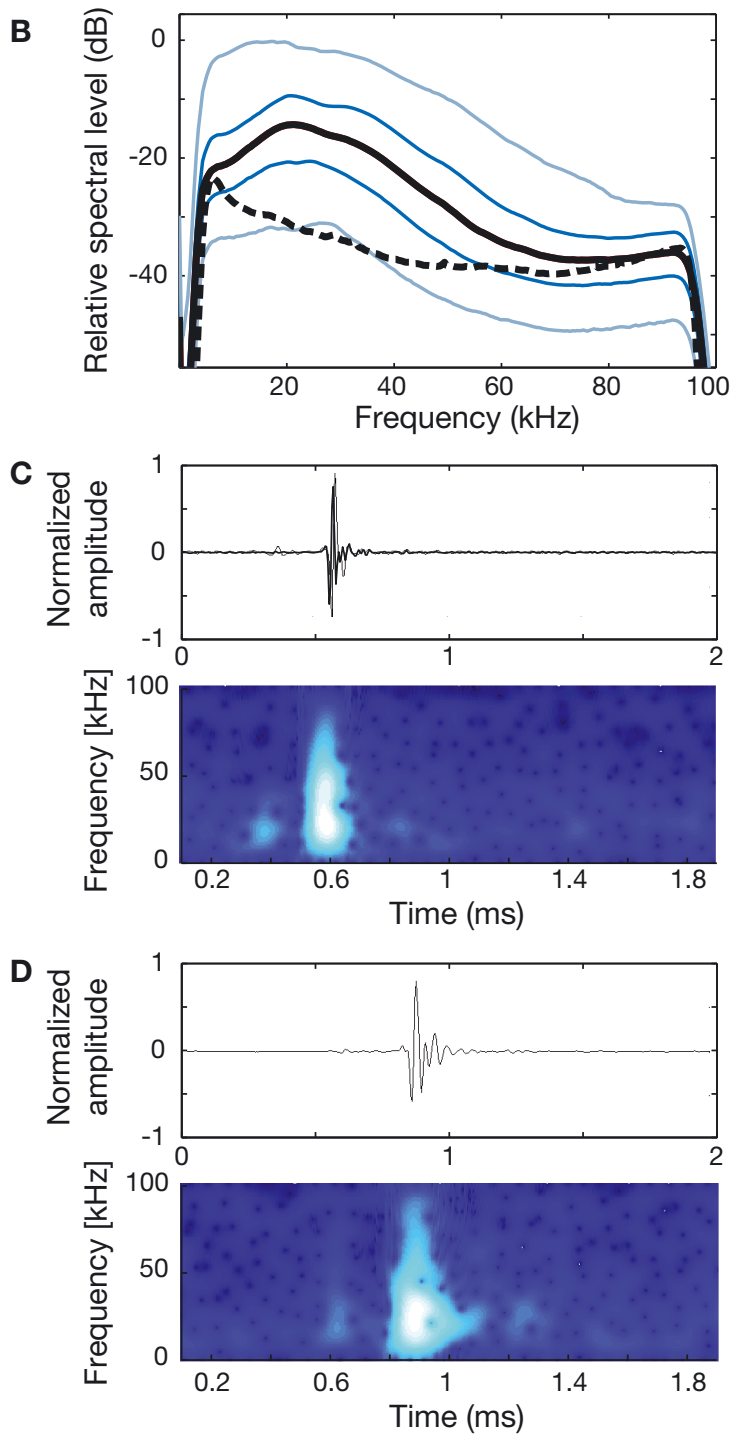

Short-finned pilot whale
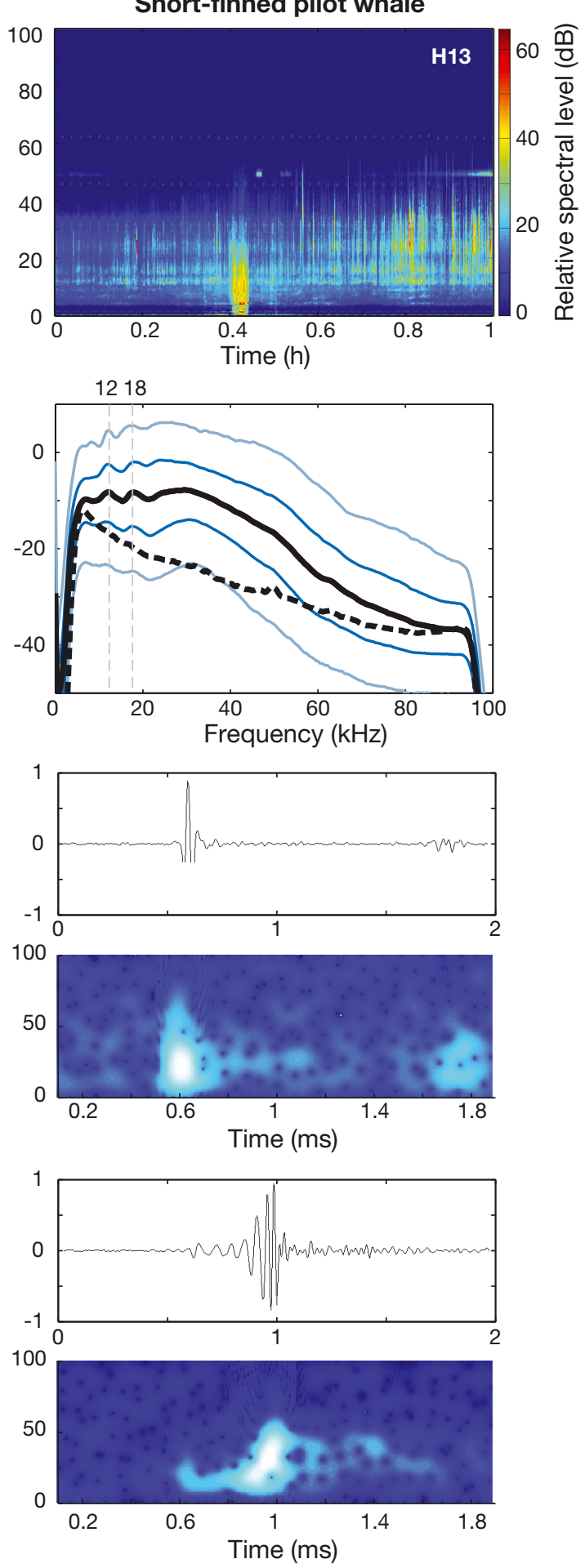

Fig. 4. Acoustic characteristics of echolocation clicks for false killer whale Pseudorca crassidens (Pc, left column) and shortfinned pilot whale Globicephala macrorhynchus (Gm, right column). (A) Long-term spectral average (LTSA, $1 \mathrm{~h}$ ) of encounter H2-Pc (left) and H13-Gm (right) with distinct species-specific spectral features. High spectral energy levels around $5 \mathrm{kHz}$ in $\mathrm{H} 2-$ Pc are whistles. (B) Median spectra of echolocation clicks (black bold line) over all high confidence acoustic encounters (see Tables 2 \& 3; Pc: 57685 clicks, Gm: 34315 clicks), median spectra of noise before each click (black dashed line), percentiles of click spectra $\left(5^{\text {th }}, 25^{\text {th }}, 75^{\text {th }}, 95^{\text {th }}\right.$; blue lines; Hann window, 512-points FFT). Spectral peaks at 12 and $18 \mathrm{kHz}$ in click spectra of short-finned pilot whale are also visible in LTSA as horizontal lines (H13-Gm, top right). (C) Time series and spectrogram of an example presumable on-axis click and (D) off-axis click for both species (32-points Gaussian-window, 512-points FFT, 97\% overlap). Longer duration and slight frequency modulation are noticeable in many of the off-axis short-finned pilot whale clicks 
A) Train \& Test - High confidence acoustic encounters

I)
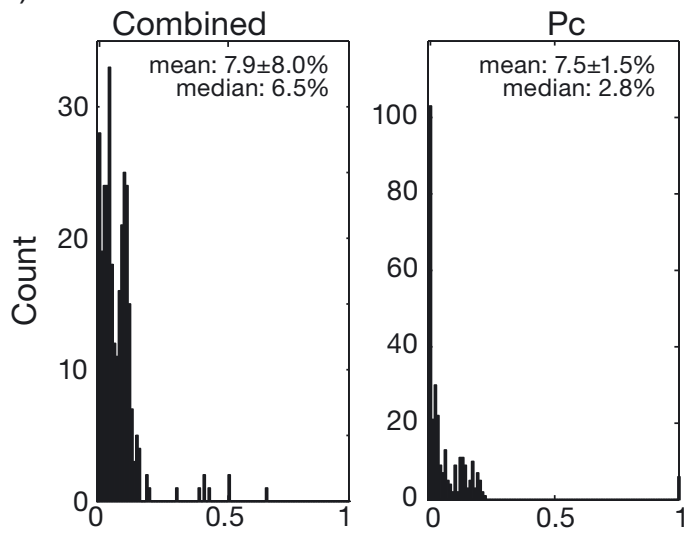

B) Test - Low confidence acoustic encounters

I)

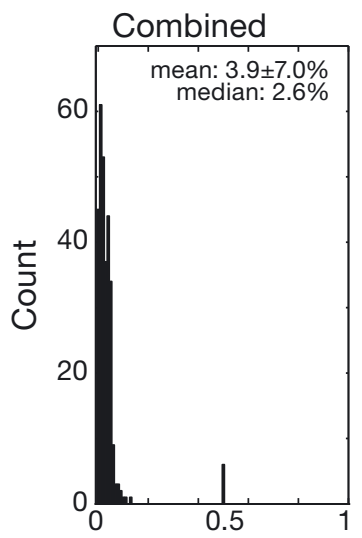

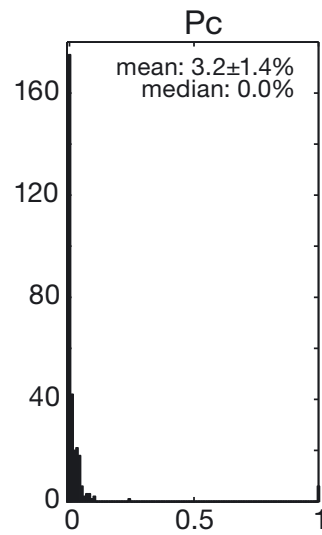

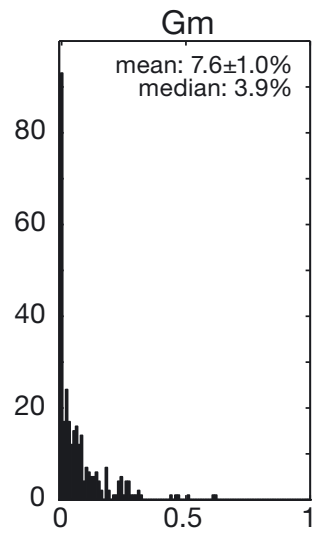

II)
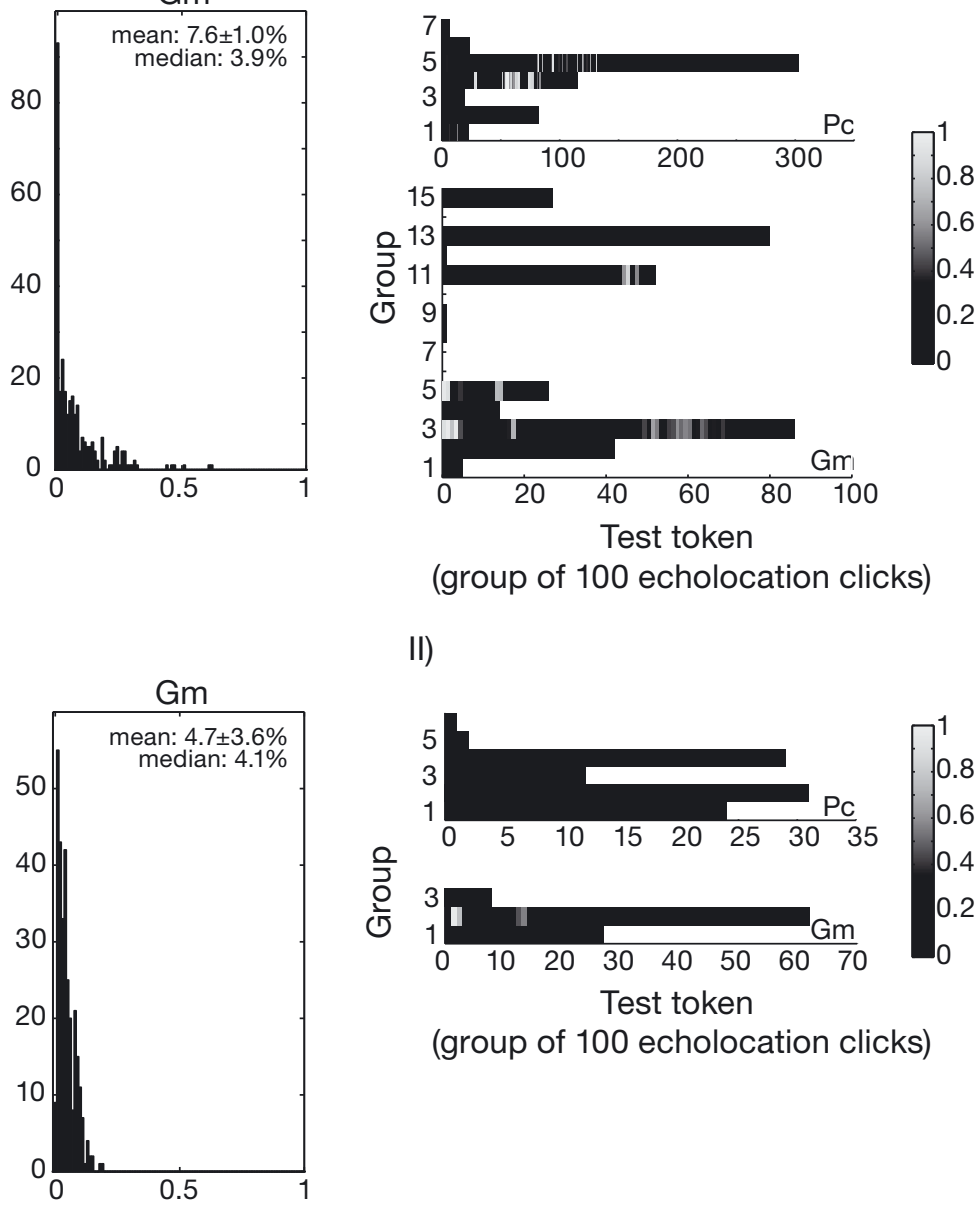

II)

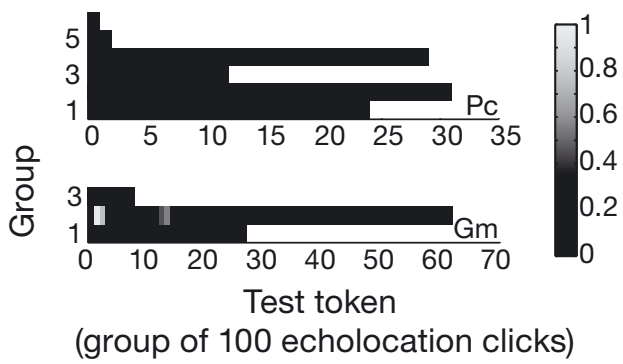

Fig. 5. Classification results from (A) training and testing on high confidence acoustic encounters and (B) testing on low confidence acoustic encounters using models constructed from high confidence data. (I) Histograms show combined (left) classification results (3 folds, 100 models), and species-specific results: Pc: false killer whale Pseudorca crassidens (middle), Gm: short finned pilot whale Globicephala macrorhynchus (right). (II) Performance of Pc (top) and Gm (bottom) test token groups of 100 echolocation clicks grouped by (A) high and (B) low confidence acoustic encounters. Grey shading in the scale bar represents the per token error rate over the 100 different models that were trained with different training data

sightings of false killer whales around the main Hawaiian Islands, short-finned pilot whales were only present during 2 sightings $(4 \%)$, and spatial overlap between the 2 species was brief in both sightings ( $\mathrm{R}$. W. Baird unpubl. data). Regardless, the consistency of the acoustic results in regards to spectral and temporal patterns as well as stable classification results support the method and results presented here. While ship-based recordings in the presence of animals are often used to describe the echolocation clicks of free-ranging animals, there are drawbacks to this method. Recordings from shallow depth hydrophones collected during ship-based acoustic surveys often have considerable noise originating from the sea surface and from the survey vessels, including acoustic sources such as breaking waves, vessel propulsion, machinery sounds, and electronic noises originating from onboard power generation or other sources. With deep water autonomous recordings, these noise sources are minimized. Also, introduced noise in recordings can be highly confounding when initially defining these species-specific click characteristics. Classifiable differences in echolocation clicks are, at times, only small differences in spectral peaks or small shifts in overall spectral energy distribution, so low noise recordings are needed for reliable classifications (Soldevilla et al. 2008, Baumann-Pickering et al. 2010, 2013a).

The data presented here (all clicks collected during acoustic encounters) are likely not comparable to other 
acoustic studies that focus on the presentation of features from on-axis clicks. Spectral and temporal parameters of echolocation clicks vary largely with the orientation of the animals' head relative to the hydrophone (Au et al. 1995, 2012a,b), their distance to it (Urick 1983), their individual hearing range (Kloepper et al. 2010), the behavioral state of the animals (Kloepper et al. 2012), as well as potentially other aspects such as the number of animals being acoustically active or the acoustic environment (Baumann-Pickering et al. in press). Given the median and percentile values in Table 4 and in comparison to published on-axis click values (Au et al. 1995, Kloepper et al. 2010, 2012), one can assume that the majority of clicks described in this article were recorded off-axis. For the purpose of passive acoustic monitoring using a single hydrophone, these intricacies of angle, distance, and behavior cannot easily be distinguished. Hence, stable features observed across recorded signals and a description of the observed variability are of interest from free-ranging species in their natural habitat. Click classification models should be able to incorporate variability in click characters without detailed knowledge of its cause and still be able to classify with adequate precision.

Species-specific peaks in the mean spectra and LTSAs of short-finned pilot whale acoustic encounters are similar to species-specific peaks reported for Pacific white-sided Lagenorhynchus obliquidens and Risso's Grampus griseus dolphins off the coast of California (Soldevilla et al. 2008), as well as for several beaked whale species (Baumann-Pickering et al. $2013 a, b)$. These click characteristics make acoustic encounters reliably identifiable to species level. Soldevilla et al. (2008) also point out that echolocation clicks with longer duration, presumably recorded off the central axis, show stronger spectral peaks for Pacific white-sided and Risso's dolphins. Hence, these spectral peaks may occur due to anatomical structures that shape off-axis echolocation signals. When spectral peaks are not an available parameter, as is the case for false killer whales, then species identification becomes more challenging (e.g. Baumann-Pickering et al. 2010, Roch et al. 2011). Another species with overlapping geographic distribution to false killer whales that may have similar broadband clicks without distinct spectral peaks could be roughtoothed dolphins Steno bredanensis, based on recent work by Rankin et al. (2015). Future work should investigate classification success of encounters including rough-toothed dolphins.

GMM classification with low error rates for false killer whale and short-finned pilot whale echoloca- tion clicks confirms the possibility of distinguishing between the signals of these species. Error rates were even lower when testing on the low confidence acoustic encounters. This further strengthens our result that the 2 observed patterns of echolocation clicks are indeed classifiable with high accuracy. The next steps for optimizing and further understanding these classification results would be to more closely investigate those test tokens (groups of 100 echolocation clicks) that had consistent errors (Fig. 5II) to establish exactly what made these clicks different from those in the correctly classified tokens. Adding to the classification accuracy would be details on how the click signals attenuate with frequency over distance and how the signal's beam pattern, along with animal heading, affects the recorded signal. Using literature values collected from a small number of individuals in captivity can be useful; however, it may be possible to collect such data in the field by deploying sensors in an array that can track animals acoustically (e.g. Wiggins et al. 2012). Furthermore, such an experiment would ideally include acoustic archival-tagged animals swimming through the array, providing fine-scale spatial and temporal swimming and acoustic behavior.

Based on our results on the classification of echolocation clicks and published work on whistle discrimination, passive acoustic monitoring of false killer whales and short-finned pilot whales has the potential to be reliable with high accuracy. This opens up new methods for management and bycatch mitigation by investigating long-term trends in behavior and ecology, in addition to including passive acoustic recorders on fishing gear or hydrophones attached to long-line fishing vessels to identify behavioral patterns, confirm species of bycaught animals or implement real-time alarm systems.

Acknowledgements. The authors thank 2 anonymous reviewers for their insightful comments. We also thank John A. Hildebrand, Erin O'Neill, Brent Hurley, Chris Garsha, and Rachel Gottlieb for instrument preparation, data collection, and analysis assistance. HARP deployments and recovery off the island of Hawai'i were undertaken with the assistance of Greg Schorr and Daniel Webster. Satellite tags were deployed by Greg Schorr, Daniel Webster and Brad Hanson. Tagging was undertaken under NMFS Scientific Research Permit No. 731-1774 issued to R.W.B. Funding for this project was provided by the NOAA Pacific Islands Fisheries Science Center and Northwest Fisheries Science Center, the US Navy (through the Living Marine Resources Program, Naval Postgraduate School, National Oceanographic Partnership Program, and Office of Naval Research), the Bureau of Ocean Energy Management, and the John F. Long Foundation. 


\section{LITERATURE CITED}

Aguilar Soto N, Johnson MP, Madsen PT, Díaz F, Domínguez I, Brito A, Tyack P (2008) Cheetahs of the deep sea: deep foraging sprints in short-finned pilot whales off Tenerife (Canary Islands). J Anim Ecol 77:936-947

Au WWL (1993) The sonar of dolphins. Springer, New York, NY

- Au WWL, Pawloski JL, Nachtigall PE, Blonz M, Gisner RC (1995) Echolocation signals and transmission beam pattern of a false killer whale (Pseudorca crassidens). J Acoust Soc Am 98:51-59

Au WWL, Branstetter B, Moore PW, Finneran JJ (2012a) The biosonar field around an Atlantic bottlenose dolphin (Tursiops truncatus). J Acoust Soc Am 131:569-576

Au WWL, Branstetter B, Moore PW, Finneran JJ (2012b) Dolphin biosonar signals measured at extreme off-axis angles: insights to sound propagation in the head. J Acoust Soc Am 132:1199-1206

Baird RW (2009) A review of false killer whales in Hawaiian waters: biology, status, and risk factors. Report prepared for the US Marine Mammal Commission, order no. E40475499. Cascadia Research Collective, Olympia, WA www.cascadiaresearch.org/hawaii/Hawaiifalsekillerwhale reviewMMC2009.pdf

Baird RW, Schorr GS, Webster DL, McSweeney DJ, Hanson MB, Andrews RD (2010) Movements and habitat use of satellite-tagged false killer whales around the main Hawaiian Islands. Endang Species Res 10:107-121

Baird RW, Hanson MB, Schorr GS, Webster DL and others (2012) Range and primary habitats of Hawaiian insular false killer whales: informing determination of critical habitat. Endang Species Res 18:47-61

Baird RW, Oleson EM, Barlow J, Ligon AD, Gorgone AM, Mahaffy SD (2013a) Evidence of an island-associated population of false killer whales (Pseudorca crassidens) in the northwestern Hawaiian Islands. Pac Sci 67:513-521

Baird RW, Webster DL, Aschettino JM, Schorr GS, McSweeney DJ (2013b) Odontocete cetaceans around the main Hawaiian Islands: habitat use and relative abundance from small-boat sighting surveys. Aquat Mamm 39:253-269

Baumann-Pickering S, Wiggins SM, Hildebrand JA, Roch MA, Schnitzler HU (2010) Discriminating features of echolocation clicks of melon-headed whales (Peponocephala electra), bottlenose dolphins (Tursiops truncatus), and Gray's spinner dolphins (Stenella longirostris longirostris). J Acoust Soc Am 128:2212-2224

Baumann-Pickering S, McDonald MA, Simonis AE, Solsona Berga A and others (2013a) Species-specific beaked whale echolocation signals. J Acoust Soc Am 134: 2293-2301

Baumann-Pickering S, Yack TM, Barlow J, Wiggins SM, Hildebrand JA (2013b) Baird's beaked whale echolocation signals. J Acoust Soc Am 133:4321-4331

Baumann-Pickering S, Roch MA, Wiggins SM, Schnitzler HU, Hildebrand JA (in press) Acoustic behavior of melon-headed whales varies on a diel cycle. Behav Ecol Sociobiol, doi:10.1007/s00265-015-1967-0

> Bradford AL, Forney KA, Oleson EM, Barlow J (2014) Accounting for subgroup structure in line-transect abundance estimates of false killer whales (Pseudorca crassidens) in Hawaiian waters. PLoS ONE 9:e90464

Brill RL, Pawloski JL, Helweg DA, Au WW, Moore PWB (1992) Target detection, shape discrimination, and signal characteristics of an echolocating false killer whale (Pseudorca crassidens). J Acoust Soc Am 92:1324-1330

Carretta JV, Oleson EM, Weller DW, Lang AR and others (2014) US Pacific Marine Mammal Stock Assessments, 2013. US Dept Commerce, Washington, DC, NOAA Tech Memo NOAA-TM-NMFS-SWFSC-532

Chivers SJ, Baird RW, Martien KM, Taylor BL and others (2010) Evidence of genetic differentiation for Hawai'i insular false killer whales (Pseudorca crassidens). US Dept Commerce, Washington, DC, NOAA Tech Memo NOAA-TM-NMFS-SWFSC-458

> Eskesen IG, Wahlberg M, Simon M, Larsen ON (2011) Comparison of echolocation clicks from geographically sympatric killer whales and long-finned pilot whales. J Acoust Soc Am 130:9-12

Forney KA, Kobayashi DR, Johnston DW, Marchetti JA, Marsik MG (2011) What's the catch? Patterns of cetacean bycatch and depredation in Hawaii-based pelagic longline fisheries. Mar Ecol 32:380-391

Herman LM, Tavolga W (1980) The communications systems of cetaceans. In: Herman LM (ed) Cetacean behavior: mechanisms and function. Wiley-InterScience, New York, NY

Ibsen SD, Krause-Nehring J, Nachtigall PE, Au WWL, Breese M (2011) Similarities in echolocation strategy and click characteristics between a Pseudorca crassidens and a Tursiops truncatus. J Acoust Soc Am 130:3085-3089

Jefferson TA, Webber MA, Pitman RL (2008) Marine mammals of the world: a comprehensive guide to their identification. Elsevier, London

Jensen FH, Marrero Perez J, Johnson M, Aguilar Soto N, Madsen PT (2011) Calling under pressure: short-finned pilot whales make social calls during deep foraging dives. Proc R Soc B 278:3017-3025

Kloepper LN, Nachtigall PE, Breese M (2010) Change in echolocation signals with hearing loss in a false killer whale (Pseudorca crassidens). J Acoust Soc Am 128: 2233-2237

Kloepper LN, Nachtigall PE, Donahue MJ, Breese M (2012) Active echolocation beam focusing in the false killer whale, Pseudorca crassidens. J Exp Biol 215:1306-1312

> Madsen PT, Kerr I, Payne R (2004) Echolocation clicks of two free-ranging, oceanic delphinids with different food preferences: false killer whales Pseudorca crassidens and Risso's dolphins Grampus griseus. J Exp Biol 207: 1811-1823

Madsen PT, Lammers M, Wisniewska D, Beedholm K (2013) Nasal sound production in echolocating delphinids (Tursiops truncatus and Pseudorca crassidens) is dynamic, but unilateral: clicking on the right side and whistling on the left side. J Exp Biol 216:4091-4102

- Mahaffy SD, Baird RW, McSweeney DJ, Webster DL, Schorr GS (2015) High site fidelity, strong associations and longterm bonds: short-finned pilot whales off the island of Hawai'i. Mar Mamm Sci, doi:10.1111/mms.12234

Martien KK, Chivers SJ, Baird RW, Archer FI and others (2014) Nuclear and mitochondrial patterns of population structure in North Pacific false killer whales (Pseudorca crassidens). J Hered 105:611-626

> Oswald JN, Barlow J, Norris TF (2003) Acoustic identification of nine delphinid species in the eastern tropical Pacific Ocean. Mar Mamm Sci 19:20-37

> Oswald JN, Rankin S, Barlow J, Lammers MO (2007) A tool for real-time acoustic species identification of delphinid whistles. J Acoust Soc Am 122:587-595 
Rankin S, Oswald JN, Simonis AE, Barlow J (2015) Vocalizations of the rough-toothed dolphin, Steno bredanensis, in the Pacific Ocean. Mar Mamm Sci, doi:10.1111/mms.12226

Rendell LE, Matthews JN, Gill A, Gordon JCD, Macdonald DW (1999) Quantitative analysis of tonal calls from five odontocete species, examining interspecific and intraspecific variation. J Zool 249:403-410

Roch MA, Klinck H, Baumann-Pickering S, Mellinger DK, Qui S, Soldevilla MS, Hildebrand JA (2011) Classification of echolocation clicks from odontocetes in the Southern California Bight. J Acoust Soc Am 129:467-475

Soldevilla MS, Henderson EE, Campbell GS, Wiggins SM, Hildebrand JA, Roch MA (2008) Classification of Risso's and Pacific white-sided dolphins using spectral properties of echolocation clicks. J Acoust Soc Am 124:609-624

Thomas JA, Turl CW (1990) Echolocation characteristics and range detection by a false killer whale (Pseudorca crassidens). In: Thomas JA, Kastelein RA (eds) Sensory abilities of cetaceans: laboratory and field evidence. Plenum Press, New York, NY, p 312-334

Editorial responsibility: Brendan Godley, University of Exeter, Cornwall Campus, UK
Urick RJ (1983) Principles of underwater sound. McGrawHill, New York, NY

Welch PD (1967) The use of fast Fourier transform for the estimation of power spectra: a method based on a time averaging over short, modified periodograms. IEEE Trans Audio Electroacoust AU-15:70-73

Wiggins SM, Hildebrand JA (2007) High-frequency acoustic recording package (HARP) for broad-band, long-term marine mammal monitoring. In: International symposium on underwater technology and workshop on scientific use of submarine cables and related technologies. IEEE, Tokyo, p 551-557

Wiggins SM, McDonald MA, Hildebrand JA (2012) Beaked whale and dolphin tracking using a multichannel autonomous acoustic recorder. J Acoust Soc Am 131: 156-163

> Yuen MML, Nachtigall PE, Breese M, Supin AY (2005) Behavioral and auditory evoked potential audiograms of a false killer whale (Pseudorca crassidens). J Acoust Soc Am 118:2688-2695

Submitted: October 10, 2014; Accepted: June 16, 2015 Proofs received from author(s): July 7, 2015 